\title{
Looking Back on Philanthropy in a Pandemic Foundation Colleagues Share Common Perspectives from Across the Pond
}

\author{
Robert J. (Bob) Reid ${ }^{1}$. Caroline Broadhurst ${ }^{2}$
}

Received: 24 September 2020 / Accepted: 2 March 2021 / Published online: 1 April 2021

(c) The Author(s), under exclusive licence to Springer Nature Switzerland AG 2021

\begin{abstract}
Over the past year, the pandemic caused havoc globally touching the lives of most people. This included emerging challenges for nonprofits on the front lines of escalating need while at the same time limiting fundraising. Scaling up to meet needs in an extreme resource constrained environment pushed many nonprofits to the brink of insolvency. Many foundations have responded effectively to this circumstance by increasing grant making, reducing red tape, and extending greater flexibility for nonprofits. In doing so, foundations have exercised unusual humility in how they positioned themselves relative to nonprofits in protecting capacity to serve intended beneficiaries. This op-ed explores the relaxing of traditional tensions between foundations and grant seekers in ways that enabled more adequate and timely responses to pressing human needs in the face of the pandemic.
\end{abstract}

Keywords Foundations · Nonprofits · Pandemic · Management · Grant making · Philanthropy $\cdot$ Collaboration

Looking Back on Philanthropy in a Pandemic

Foundation Colleagues Share Common Perspectives from Across the Pond

Robert J. (Bob) Reid, PhD \& Caroline Broadhurst

The immediate past CEO of a US foundation and Deputy Executive of a UK foundation share strikingly similar observations about encouraging philanthropic

Robert J. (Bob) Reid, PhD - President of Edge Philanthropy, LLC and Immediate Past CEO of the JF Maddox Foundation.

Robert J. (Bob) Reid

rjreid@okstate.edu

Caroline Broadhurst

caroline.broadhurst@rankfoundation.com

1 Edge Philanthropy, JF Maddox Foundation, Rio Rancho, NM, USA

2 Rank Foundation, London, UK 
practices during the pandemic. Their observations offer insight into the soulfulness of philanthropy in exceptionally difficult times.

Rediscovering Foundation Humility During the Pandemic

Robert J. (Bob) Reid, PhD

Edge Philanthropy LLC, Previously CEO at the JF Maddox Foundation

Rio Rancho, New Mexico

In a 2014 study, The Opacity of Private Philanthropy, grant seekers complained that foundations were difficult to access, mysterious, opaque, and unilaterally demanding (Reid, 2015, 2018a). Grant recipients reported they were often forced to adopt foundation priorities and strategies rather than enjoining foundations into their own longstanding work. A palpable disparity in power between funders and fund seekers reportedly made partnering with foundations especially difficult and has given rise to what grant seekers called foundation hubris.

Also observed in this study was a tendency for foundations to be inwardly focused, pursuing primarily their own interests rather than engaging grantees and communities in co-identifying priorities and co-creating strategies. Foundations have often been criticized for being ineffective collaborators with other foundations, grantee partners, and communities. Some grantees suggested foundations are out of touch with, and possibly even disinterested in, the realities they routinely confront. Nonprofits reported that they were seldom included by foundations in developing new strategies (Reid, 2015). Further, efforts to incrementally fund specific projects rather than providing general support to agencies have resulted in diversion of valuable agency attention and resources.

Grantees reported that foundations were increasingly seeking to drive the philanthropic agenda with internally developed and elaborate models for social change relegating nonprofits to mere instruments of implementation rather than engaging them as valued partners (Reid, 2015, 2018a). Moving increasingly toward becoming architects of strategy rather than supporting pre-existing players in the social change space may be fundamentally altering the role of philanthropy, positioning foundations as unilateral leaders rather than supporters of change. The study found that grantees were disinclined to express dissonance about or discomfort with changing foundation roles (Reid, 2015, p.81). Doing so might injure prospects for accessing much needed financial resource.

Over the past couple of decades, foundations have assumed a more dominant, forward-leaning posture with respect to designing approaches, and imposing onesided accountability in pursuing desired social change. Foundations have become increasingly less patient in pursuing social change and exercising influence within their grantee communities while striving to define and drive desired social change as opposed to supporting the longstanding role of nonprofits in improving society. This has resulted in new practices, as well as efforts to lever the resources and operating capacities of grantees for the exclusive benefit of foundation initiatives. Rather than supporting the work of nonprofits as they attempt to effect change, many foundations have themselves become proactive agents of change by using their grant making resources in highly prescriptive ways.

Foundations have acquired elevated expectations regarding the scale and pace of change seeking to accelerate progress and expand impact disproportionately greater 
than their grant making resources (Reid, 2018a). Terms like strategic, venture, or impact philanthropy have become increasingly present in foundation lexicon. While often built upon elaborate, evidence-based logic models, highly prescriptive forms of philanthropic practice might accelerate impact but also be disruptive to strategies long embraced by grantees. The power differential in foundation-grantee relations can give way to foundation hubris where foundations, intended or not, dictate grantees' actions rather than engaging them as genuine partners.

Though foundations no doubt have much to contribute beyond merely writing checks, it seems that the growing footprint of foundation influence has yet to find a place in which nonprofits can participate and contribute as genuine collaborators. As philanthropy's influence accelerates in social change, care must be exercised in just how far to swing the pendulum of foundation influence where power is too often resource-driven and disproportionate between players in the space of social change (Reid, 2018b).

While the challenges cited earlier remain important matters to consider, many foundations have responded in highly empathic and quite effective ways to the COVID-19 pandemic. It appears philanthropy rolled up its sleeves, for the most part, and humbly went to work in addressing serious needs. Evidence suggests that foundations found a coherent footing in advancing public policy while also demonstrating empathic tendencies toward nonprofits on the front edge of the pandemic. Foundations were observed adeptly showing ability to contribute at multiple levels - helping to infuse both intellectual and financial assets in ways that were genuinely helpful to society.

At the same time, foundations demonstrated deep, soulful resolve as they accelerated grant making in times when their endowments were sinking. Foundations such as Ford, McArthur, and Duke even acquired debt to meaningfully accelerate much-needed grant making capacity. Gates, Robert Wood Johnson, and Ford used their considerable reputational, intellectual, and financial resources to back scientific research, promulgate accurate public health information, and advance public policy with the objective of reducing viral spread while searching for a vaccine.

While these mega-foundations have offered great value at a macro-level, many small to mid-sized foundations empowered grantees at the micro-level. The mega foundations have demonstrated considerable skill and finesse in how they pursued their ambitious objectives and their great contribution should be acknowledged. However, this op-ed is intended to focus on a palpable change in philanthropic practice observed among small to mid-sized foundations in their work at the local level.

Many smaller foundations also accelerated their grant making while demonstrating an acute awareness of rapidly changing and evolving needs. By stark contrast to concerns previously expressed, grantees advised that these smaller foundations seemed uncharacteristically sensitive to, and supportive of, their organizations during recent months (Harrison-Byrne, 2020). Many foundations intentionally shifted power to their grantees, allowing them greater freedom to establish priorities and adapt to changing circumstances. In these cases, foundations became important sources of encouragement and essential resources rather than seeking to be architects of strategy.

The extent and pace of the destruction unleashed by the COVID-19 pandemic on global economies and the resulting increase in the most basic of humanitarian needs seemed, at least temporally, to put in check perceptions of foundation hubris. Disasters 
have a way of changing the rules people live by. In the face of the pandemic, foundations demonstrated greater interest in supporting the most essential of human services - food support, housing, and medical services for rapidly displaced people. In these dynamic and uncertain times, many foundations demonstrated willingness to shift from strategic to tactical engagements in ways that were highly responsive to, and less demanding of, grantees - allowing nonprofits to lead on the ground in responding to emerging needs.

For example, one foundation in the Southwest of the United States issued preemptive, unsolicited grants to many of its grantees. The foundation knew its grantees well and realized many were at risk of becoming insolvent. By making these pre-emptive emergency grants, the foundation invested in, and preserved, essential nonprofit capacity. Grantees had complete freedom about how to use these emergency grants. Several foundations were observed providing funds to help fill emerging gaps in nonprofit budgets arising out of cancelled fundraising events. The result of such emergency grant making was that important grantees survived, and therefore, their relationships with foundations were meaningfully advanced.

The pandemic resulted in economic contraction and depression-level unemployment on a scale not experienced in a generation. Accordingly, this has been a time in which foundations needed to help bail water, rather than chart new courses, for their grantee partners. At the micro level, several examples of highly responsive grant making with the intent of preserving and empowering grantee organizations were observed such as the previously cited examples. For many grantee organizations, the pandemic caused declining revenue at the very time in which demand for services escalated, leaving them at serious risk of becoming insolvent and non-viable. In response, many foundations created special COVID-19 emergency funds; streamlined grant application processes, eliminated burdensome reporting requirements, expanded categories of grant making, and significantly increased giving levels.

The highly engaged and empathic grant making practices observed during the pandemic have been life sustaining for many nonprofits, arguably leading to more collegial relations between certain foundations and their grantee organizations. There is evidence that foundations have achieved highly collegial relations with select grantees (Reid, 2018c). Hopefully, lessons arising out of approaches employed during the pandemic will prompt greater humility in foundation grant making prospectively. In these unusual times foundations have perhaps rediscovered the value of empowering nonprofits and promoting their resilience. While there may still be opportunity for foundations to engage in developing more effective strategies for desired social change, perhaps the pandemic also reintroduced the utility of humility in philanthropic practice for the purpose of empowering grantees.

The remarkable responsiveness, flexibility, and collaborative practices employed by many foundations during the pandemic are indeed laudable. While foundations have much to offer in seeking to enhance effectiveness of nonprofit strategies, hopefully they will continue to find ways to empower, and more effectively partner with, nonprofits in ways that lessen power disparities and build genuine collegiality. Recent experiences suggest humility is essential to empathic and effective philanthropy.

Following the pandemic, the foundation community might want to reassess itself in discovering ways to better balance intellectual and financial resources with effective engagement of, and greater respect for, nonprofits. Pursuit of meaningful social progress 
requires a big tent involving many more players than merely foundations. Perhaps it is time to reconsider how philanthropy's role in serving humanity can be more inclusive thereby broadening the tent under which collective partnerships with nonprofits is possible. Foundations exhibited capacity for soulful resolve, appropriate humility, and effective engagement during the recent public health crisis. Hopefully, institutional philanthropy will build further on the special work of foundations well beyond the pandemic.

The Renaissance of Humility in Philanthropic Organisations

Caroline Broadhurst

Rank Foundation

London, England

It is true that we should never waste a crisis. And the COVID-19 pandemic offered philanthropic organisations as many opportunities as challenges. The world as we knew it changed and so too the outlook and experience of those within it. We faced unprecedented levels of widespread unemployment, isolation among the elderly, discontentment among the young and racial fractures. Although we may have awakened to these wicked challenges in 2020, they had been simmering for some time, while leaders who could affect change, including government and philanthropic organisations, pursued the good-doing and populist agendas. Factor in a virus that technically could infect and affect us all, the traditional power balance between giver and receiver, leader and follower or foundation and grantee, ebbed away to allow a new, authentic sense of partnership; we really were all in this together.

As early as April 2020, many United Kingdom (U.K.) small and medium-sized foundations galvanised support and demonstrated leadership in the face of the pandemic exerting collective flexibility towards existing grantees in terms of use of funds and reporting procedures (London Funders, 2020). This was followed by a wave of emergency programmes to help cash-strapped charities to continue to work, remotely and safely. When the pandemic impacts started to look insurmountable, many foundations released in-year funds to build resilience within charities and some foundations took the brave steps to use additional funds from their endowments. The 'rainy day' had arrived and buckets of cash were needed, urgently. But how might this drop in the ocean really make a difference to the survival of those charities who in turn were facing 'once in a generation' demands from those they sought to help?

In the first 3 months of the pandemic it is estimated that $£ 4.3$ billion disappeared from the U.K. social sector (Whitehead, 2020). Fundraising events cancelled, many staff 'furloughed' and most foundations looked to support those they knew rather than opening up to new applicants, the majority of charities faced significant reductions in income at a time when demand for their services was soaring. They looked to the government for support, but it was prioritising primary health care, understandably. And they looked to foundations to reframe the traditional relationship. With no time to dance around 'foundation fit', philanthropic organisations needed to set aside their own ideas, their own ambition to save the world and to listen and respond to the charities they served. 
This was an urgent call for humble leadership in the philanthropic sector. Nielsen and Marrone (2018) described those with humility having, 'a self-view of interdependence with others and feel deeply motivated to contribute to the success of their relationships and to fulfill their roles as productive and helpful relationship partners'. A humble foundation is not quiet one, meekly and discreetly transferring cash. A humble foundation uses all its resources; its time, talent, treasure, and voice to create the changes its grantees seek.

In 'Humble Leadership' authors Schein and Schein (2018) recognized this call for a reimagined form of leadership that coincides with emerging trends of relationship building, complex group work, diverse workforces, and cultures in which everyone feels psychologically safe. Humble Leadership calls for "here and now" humility based on a deeper understanding of the constantly evolving complexities of intergroup relationships that require shifting our focus towards the process of group dynamics and collaboration; ' humble leadership at all levels and in all working groups will be the key to achieving the creativity, adaptiveness, and agility that organizations will need to survive and grow.'

In any authentic relationship there is an unwritten agreement of give and take, of who takes the lead and who listens and guides. 2020 was a time for foundations to listen, to trust and to support their partner grantees in different, more engaged ways. Charities knew their own needs best, especially in identifying the needs of the most vulnerable, the lonely and the forgotten. But they also needed the backup and support from grantmakers willing to listen and consult in more collaborative ways.

We can learn from periods in history when philanthropists, mostly on an individual basis, really did make a difference in the world and we admire their achievements. We remember their names, not the names of the charities and communities they funded. Here we had a game changing opportunity for foundations to step aside from the limelight, with grace, and put all their energies into supporting the real protagonists, those who tirelessly served the most vulnerable communities, where the COVID-19 pandemic had exposed widespread inequality and disadvantage from the cradle to the grave.

We must not waste the opportunities afforded by the greatest global pandemic of modern times. Our post-COVID community of small and medium-sized foundations can rediscover, with a spirit of generosity and empathy, its humble mettle, a new tool in the philanthropic toolkit. With courage and humility, foundations have the wherewithal to pass the mantel to their partner grantees, those closest to the pain, and those best placed to alleviate it.

\section{Key Takeaways}

While the observations reported in this Op-Ed derived from different continents and cultures, they are remarkably similar. From both sides of the pond, we witnessed effective emergence of leadership from within the foundation community that reframed grantee engagement in the face of a pandemic. Many foundations subordinated their resource-based power in favor of engaging and empowering their grantee partners.

In doing so, Foundations were acutely responsive to the very challenging circumstances confronting nonprofits while genuinely supporting grantee knowledge of 
on-the-ground needs of those they served. This gave rise to engagements that repositioned the power for impact to nonprofits on the frontlines of service delivery. A humble form of foundation leadership emerged where foundations assumed the role of supporting agents rather than seeking to be architects of strategy, giving way to more effective partnerships with grantees.

Perhaps, the real power of institutional philanthropy was elevated through a humble repositioning of foundation roles in responding to many serious consequences of the pandemic. Rather than demonstrating funder hubris, many foundations exhibited empathic orientation toward grantee partners - seeking to put wind under the wings of grantees instead of wielding resource-based power and imposing the anvil of unilaterally imposed accountability.

As my UK colleague suggests, we should never waste the opportunity of a disaster for self-assessment as the relatively new field of philanthropy continues to evolve. The pandemic may have brought out the best in us, but the pungent memories of this experience should not be short lived. Instead, we should look back on this experience as a rich opportunity to learn more about ourselves and those we seek to support.

\section{References}

Harrison-Byrne, T. (2020). Impact of COVID-19 - John Ellerman Foundation research with grantees and unsuccessful applicants. NFPSynery: https://nfpsynergy.net/blog/new-research-finds-fundershave-responded-well-outbreak-covid-19?mc_cid=1b48a47585\&mc_eid=d25a8487df\#downloads. Accessed 10 Sept 2020.

London Funders (2020) Press release: More than 250 funders have signed the covid-19 funder statement: https://londonfunders.org.uk/our-blog/press-release-more-250-funders-have-signed-covid-19funder-statement. Accessed 19 Sept 2020.

Nielsen, R., \& Marrone, J. A. (2018). Humility: Our current understanding of the construct and its role in organizations. International Journal of Management Reviews, 20(4), 805-824.

Reid, R. J. (2015). Opacity of private philanthropy. Unpublished PhD Dissertation, Oklahoma State University, Still water, Oklahoma. https://shareok.org/bitstream/handle/11244/45378/Reid_okstate_ 0664D_14270.pdf. Accessed 19 Sept 2020.

Reid, R. J. (2018a). Foundation transparency: Opacity - it's complicated. The Foundation Review, 10(1), 2020. https://doi.org/10.9707/1944-5660.1408. Accessed 19 Sept 2020.

Reid, R. J. (2018b). Contextualizing Foundation-Grantee Relations. New Mexico Association of Grantmakers: https://mailchi.mp/8b9af548c208/october-2018-e-newsletter?e=1c11eb4fd5. Accessed 19 Sept 2020.

Reid, R.J. (2018c). Blurred boundaries: A new world for some foundation/grantee partnerships. Nonprofit Quarterly: https://nonprofitquarterly.org/blurred-boundaries-a-new-world-for-some-found ation-grantee-partnerships/ Accessed 19 Sept 2020.

Schein, E. H., \& Schein, P. A. (2018). Humble leadership: The power of relationships, openness, and trust. Berrett-Koehler Publishers.

Whitehead, H. (2020). Charities set to lose £4bn over 12 weeks due to Covid-19 pandemic. Civil Society. https://www.civilsociety.co.uk/news/charities-face-closure-as-sector-set-to-lose-4bn-over-12-weeks. html. Accessed 19 Sept 2020.

Publisher's Note Springer Nature remains neutral with regard to jurisdictional claims in published maps and institutional affiliations. 